\title{
Compressive Strength of Concrete Containing Silica Fume
}

\author{
Drago Saje ${ }^{1}$, Franc Saje ${ }^{2}$ and Jože Lopatič ${ }^{3}$ \\ University of Ljubljana, Faculty of Civil and Geodetic Engineering, \\ Jamova 2, SI-1000 Ljubljana, Slovenia \\ E-mail: dsaje@fgg.uni-lj.si
}

\begin{abstract}
The current paper presents the findings of a long-term study, from the beginning of concrete hardening up to the age of concrete of one year, on the compressive strength of high strength concrete containing silica fume (SF). The concrete mixtures were prepared with a cement content of $400 \mathrm{~kg} \mathrm{~m}^{-3}$ and water-binder ratio (W/B) of 0.4 . The percentage of SF in the binder of the investigated concretes was in the range between 0 and $15 \%$. Three different types of cement were used. It was found that the compressive strength of concrete containing SF increased in the first days of concrete hardening more slowly than for concrete without the mineral addition. After the age of concrete of approximately seven days the compressive strength of concretes with added SF was larger than of comparative concrete without SF, due to pozzolanic reaction and packing effect. The effect of SF content on the compressive strength development is reduced by using concrete with cement of higher specific surface area.
\end{abstract}

Keywords: high-performance concrete, high-strength concrete, silica fume, pozzolanic reaction, packing effect, compressive strength.

\footnotetext{
${ }^{1}$ Ph.D., Teaching Assistant

${ }^{2}$ Ph.D., Associate Professor

${ }^{3}$ Ph.D., Assistant Professor
} 


\section{INTRODUCTION}

In order to make concrete more sustainable and durable, moderen binders contain supplementary cementitious materials, such as silica fume SF. The mechanical properties of the concrete change due to the long-term process of the binder hydration. The cement hydration, originating from the chemical reaction between Portland cement and water, results in the formation of hydrated cement paste, which is an essential element of concrete strength. In the hydration process, however, beside cement also SF takes part. Adequate use of SF can significantly improve the mechanical properties of the concrete as well as its durability. In the process of concrete hardening SF contributes to its strength through pozzolanic reactions and through the packing effect.

Hydration and pozzolanic reactions are chemical reactions between Portland cement and water $\left(\mathrm{H}_{2} \mathrm{O}\right)$ and between the hydration product - calcium hydroxide $\left(\mathrm{Ca}(\mathrm{OH})_{2}\right), \mathrm{SF}$ and water, respectively (see expression (1) to (3)). Portland cement consists of cement clinker, represented by four main minerals: alite $\left(3 \mathrm{CaO} \cdot \mathrm{SiO}_{2}\right.$ or $\left.\mathrm{C}_{3} \mathrm{~S}\right)$, belite $\left(2 \mathrm{CaO} \cdot \mathrm{SiO}_{2}\right.$ or $\left.\mathrm{C}_{2} \mathrm{~S}\right)$, aluminium phase, ferrite phase - holders of cement properties. The predominant share goes to alite and belite. In the cement clinker there are between 45 and $60 \%$ of alite and between 30 and $40 \%$ of belite. SF normally contains more than $90 \%$ of silicon dioxide $\left(\mathrm{SiO}_{2}\right)$.

Alite hydration: ( $3 \mathrm{CaO} \cdot \mathrm{SiO}_{2}$ ali $\left.\mathrm{C}_{3} \mathrm{~S}\right)$ :

$2\left(3 \mathrm{CaO} \cdot \mathrm{SiO}_{2}\right)+6 \mathrm{H}_{2} \mathrm{O} \Rightarrow 3 \mathrm{CaO} \cdot 2 \mathrm{SiO}_{2} \cdot 3 \mathrm{H}_{2} \mathrm{O}+3 \mathrm{Ca}(\mathrm{OH})_{2}$

Belite hydration: $\left(2 \mathrm{CaO} \cdot \mathrm{SiO}_{2}\right.$ ali $\left.\mathrm{C}_{2} \mathrm{~S}\right)$ :

$2\left(2 \mathrm{CaO} \cdot \mathrm{SiO}_{2}\right)+4 \mathrm{H}_{2} \mathrm{O} \Rightarrow 3 \mathrm{CaO} \cdot 2 \mathrm{SiO}_{2} \cdot 3 \mathrm{H}_{2} \mathrm{O}+\mathrm{Ca}(\mathrm{OH})_{2}$

The product of cement mineral hydration - calcium silicate hydrate $\left(3 \mathrm{CaO} \cdot 2 \mathrm{SiO}_{2} \cdot 3 \mathrm{H}_{2} \mathrm{O}\right.$ or $\left.\mathrm{C}-\mathrm{S}-\mathrm{H} \mathrm{gel}\right)$ is the strength holder of hardened cement paste. The by-product of the cement mineral hydration - calcium hydroxide - actually does not contribute to its strength.

Pozzolanic reaction:

$3 \mathrm{Ca}(\mathrm{OH})_{2}+2 \mathrm{SiO}_{2}+3 \mathrm{H}_{2} \mathrm{O} \Rightarrow 3 \mathrm{CaO} \cdot 2 \mathrm{SiO}_{2} \cdot 3 \mathrm{H}_{2} \mathrm{O}$

The packing effect of the mineral additions is of physical nature, without chemical reaction $/ 1,2 /$. The average diameter of the SF grain is between 0.1 and $0.2 \mathrm{~mm}$, which represents approximately $1 \%$ of the diameter of Portland cement grain $/ 3 /$. Fine particles fill the voids within the cement paste. The cement paste and the transition zone between aggregate and the cement paste are more homogeneous and less porous $/ 4 /$. As a consequence, the compressive strength of concrete increases. 


\section{EXPERIMENTAL PROCEDURE}

\subsection{Materials and mix proportions}

When preparing the experimental concrete mixtures, two types of coarse stone aggregate, each with a maximum grain size of $16 \mathrm{~mm}$, were used, together with fine sand. The first type of aggregate consisted of washed and crushed limestone aggregate from the separation plant at Kresnice, and of fine sand from a sandpit at Moravce. The second type of aggregate was, apart from the fine sand from the same sand-pit, mainly of metamorphic origin. This aggregate consisted of the fractions $2 / 4,4 / 8,8 / 11$ and $11 / 16$ from Bleiberg in Austria, whereas the fraction $0 / 2$ was of magmatic origin, and came from Kraljev vrh in Croatia $/ 5 /$.

When preparing the concrete mixtures, three different types of cement were used: CEM II/A-S 42.5R and CEM 1 52.5R, and a cement with a low heat of hydration: CEM I 42.5LH, all three of which are produced at the cement-works at Anhovo. The composition of the clinker in these cements is shown in Table 1. Chemical composition and physical properties of SF are shown in Table 2.

Table 1

The mineral composition of the used types of cement clinker (Bogue).

\begin{tabular}{|c|c|c|c|c|c|}
\hline \multirow{2}{*}{ Type of cement } & \multirow{2}{*}{ Type of cement clinker } & \multicolumn{4}{|c|}{ Clinker minerals } \\
\hline & & $\mathrm{C}_{3} \mathrm{~S}$ & $\mathrm{C}_{2} \mathrm{~S}$ & $\mathrm{C}_{3} \mathrm{~A}$ & $\mathrm{C}_{4} \mathrm{AF}$ \\
\hline $\begin{array}{c}\text { CEM II/A-S 42.5R } \\
\text { CEM } 152.5 \mathrm{R}\end{array}$ & Normal clinker & $64 \%$ & $15 \%$ & $9 \%$ & $9 \%$ \\
\hline CEM I 42.5LH & Clinker with a low heat of hydration & $34 \%$ & $46 \%$ & $1.5 \%$ & $15 \%$ \\
\hline
\end{tabular}

Table 2

Chemical composition and some physical characteristics of SF.

\begin{tabular}{clr}
\hline Chemical composition of $\mathrm{SF}$ & $\mathrm{SiO}_{2}$ & \\
& $\mathrm{Al}_{2} \mathrm{O}_{3}$ & $95.50-95.90 \%$ \\
& $\mathrm{Fe}_{2} \mathrm{O}_{3}$ & $0.13-0.17 \%$ \\
& $\mathrm{CaO}$ & $0.09-0.12 \%$ \\
& $\mathrm{SiC}$ & $0.35-0.55 \%$ \\
& $\mathrm{MgO}$ & $1.10-1.60 \%$ \\
& $\mathrm{SO}_{3}$ & $0.25-0.30 \%$ \\
& $\mathrm{~N}_{2} \mathrm{O}$ & $0.20-0.30 \%$ \\
& $\mathrm{~K}_{2}$ & $0.10-0.15 \%$ \\
& & $0.45-0.60 \%$ \\
\hline Physical characteristics of SF & & \\
Specific gravity & & $2200 \mathrm{~kg} \mathrm{~m}^{-3}$ \\
Specific surface & & $21-23 \mathrm{~m}^{2} \mathrm{~g}^{-1}$ \\
Particle size (80\%) & & $0.1-0.3 \mu \mathrm{m}$ \\
Humidity & $0.25-0.30 \%$ \\
\hline
\end{tabular}


In order to achieve higher strengths, part of the cement was replaced with the mineral additive SF, in the dry state.

In the case of concrete mixes with low W/B ratios, adequate workability was achieved by adding a superplasticizer. The new generation liquid polycarboxylate superplasticizer "Cementol Zeta S" was used, as well as the superplasticizer "Antikorodin". According to its chemical composition Cementol Zeta S is a polycarboxylate, whereas Antikorodin is a powder mixture of SF and a superplasticizer which, according to its chemical composition, is a sulphonated naphthalene-formaldehyde condensate. All these additives, both mineral and chemical, are manufactured by the factory of chemical products, TKK, of Srpenica. The compositions of the experimental concrete mixes are presented in Table 3.

The common denominator of all the concrete mixes was the same workability of the mix, based on the slump of the fresh concrete mix. According to the European norms EN 206/6/, the selected workability has the designation $\mathrm{S4}$, which corresponds to a slump within the limits $160-210 \mathrm{~mm}$, with a permissible deviation of $\pm 30 \mathrm{~mm}$.

\section{Table 3}

The compositions of the experimental concrete mixes.

\begin{tabular}{lccccccccc}
\hline Mix designation & $\mathrm{A}-00$ & $\mathrm{~A}-10$ & $\mathrm{~A}-\mathrm{I}$ & $\mathrm{B}-00$ & $\mathrm{~B}-10$ & $\mathrm{C}-00$ & $\mathrm{C}-10$ & $\mathrm{D}-00$ & $\mathrm{D}-10$ \\
\hline Type of aggregate & $(\mathrm{K})$ & $(\mathrm{K})$ & $(\mathrm{K})$ & $(\mathrm{K})$ & $(\mathrm{K})$ & $(\mathrm{B})$ & $(\mathrm{B})$ & $(\mathrm{K})$ & $(\mathrm{K})$ \\
\hline Fine aggregate $0-4\left[\mathrm{~kg} \mathrm{~m}^{-3}\right]$ & 1134 & 1130 & 1126 & 1135 & 1130 & 1206 & 1202 & 1144 & 1138 \\
\hline Coarse aggregate 4-16 $\left[\mathrm{kg} \mathrm{m}^{-3}\right]$ & 755 & 752 & 750 & 756 & 752 & 820 & 817 & 762 & 758 \\
\hline Type of cement & $(\mathrm{X})$ & $(\mathrm{X})$ & $(\mathrm{X})$ & $(\mathrm{Y})$ & $(\mathrm{Y})$ & $(\mathrm{X})$ & $(\mathrm{X})$ & $(\mathrm{Z})$ & $(\mathrm{Z})$ \\
\hline Quantity of binder $\left[\mathrm{kg} \mathrm{m}^{-3}\right]$ & 400 & 400 & 400 & 400 & 400 & 400 & 400 & 400 & 400 \\
\hline Content of SF $[\%$ of binder] & - & 10 & 15 & - & 10 & - & 10 & - & 10 \\
\hline W/B ratio & 0.40 & 0.40 & 0.40 & 0.40 & 0.40 & 0.40 & 0.40 & 0.40 & 0.40 \\
\hline $\mathbf{f}_{\mathrm{cm}, 28 d a y}[\mathrm{MPa}]$ & 68.9 & 80.6 & 80.2 & 74.9 & 85.0 & 87.1 & 89.2 & 56.9 & 74.0 \\
\hline
\end{tabular}

Key:

(K)Kresnice (sedimentary origin)

(B) Bleiberg, Kraljevi vrh (mainly metamorphic origin)

(X)CEM II/A-S 42,5R (Blaine $\left[\mathrm{m}^{2} \mathrm{~kg}^{-1}\right]=355,15 \%$ of blast furnance slag)

(Y)CEM I 52,5R (Blaine $\left[\mathrm{m}^{2} \mathrm{~kg}^{-1}\right]=440$ )

(Z) CEM I 42,5 LH (Blaine $\left[\mathrm{m}^{2} \mathrm{~kg}^{-1}\right]=367$ )

\subsection{Mechanical Testing}

The uniaxial compressive strength of the investigated concretes was determined on concrete cubes having edge dimensions of $\mathrm{a}=15 \mathrm{~cm}$, using a $5000 \mathrm{kN}$ capacity electromechanical testing machine for static compressive tests. Values of the compressive strengths of the investigated concretes were measured at the following ages: 1 day, and 3, 7, 28, 56, 90, 180, and 360 days. The compressive strengths of the investigated concretes were also measured at ages of less than one day, and thus the actual development over time of the 
compressive strength of these concretes was recorded from the very beginning of the hardening process. The test specimens for the compressive strength tests were, except for those which were tested before the age of one day, removed from their moulds after 24 hours, and kept in water at room temperature until the test was performed.

\section{RESULTS AND DISCUSSION}

In the text which follows an analysis has been performed of the time development of the uniaxial compressive strength of nine different types of concrete mixes. The concrete cubes with edge dimensions of a $=15 \mathrm{~cm}$, on which the compressive strength of the concrete was measured, had an age of between several hours and up to one year. This analysis of the time development of the compressive strength of the concrete included the effect of SF. The compressive strength of concrete presented in the Table 3 and in the diagrams in the text which follows represents the average value of at least three, or more, measured values of the compressive strength of the same concrete.

\section{Table 4}

The average values of the compressive strength of the investigated concretes at different ages.

\begin{tabular}{ccccccccc}
\hline & \multicolumn{7}{c}{ The age of concrete } \\
\cline { 2 - 10 } & \multicolumn{1}{c}{ The average value of the compressive strength of concrete in MPa } \\
\cline { 2 - 10 } A-00 & 32.3 & 50.7 & 60.0 & 68.9 & 77.7 & 77.8 & 81.0 & 82.1 \\
\hline A-10 & 26.4 & 51.2 & 62.4 & 80.6 & 85.6 & 87.3 & 93.2 & 97.8 \\
\hline A-15 & 22.8 & 47.6 & 61.8 & 80.2 & 89.4 & 92.9 & 90.7 & 94.9 \\
\hline B-00 & 42.9 & 60.2 & 67.1 & 74.9 & 81.1 & 78.9 & 84.7 & 91.6 \\
\hline B-10 & 41.6 & 58.9 & 70.1 & 85.0 & 84.4 & 90.1 & 90.9 & 93.3 \\
\hline C-00 & 28.0 & 56.4 & 75.3 & 87.1 & 87.8 & 89.6 & 95.6 & 96.0 \\
\hline C-10 & 22.7 & 53.1 & 73.3 & 89.2 & 100.0 & 99.4 & 107.1 & 108.9 \\
\hline D-00 & & 23.3 & 41.6 & 56.9 & 66.7 & 69.3 & 72.2 & $\mathbf{8 1 . 1}$ \\
\hline D-10 & & 23.3 & 45.0 & 74.0 & 84.4 & 86.7 & 92.4 & 100.4 \\
\hline
\end{tabular}

The effect of the quantity of SF on the time development of the compressive strength of the investigated concretes is shown in Figures. 1 to 8.

Figures 1 and 2 show the time development of the compressive strength of the three concretes designated A-00, A-10, A-15, with the W/B ratio 0.40 . These concretes differed with regard to the quantity of SF they contained $(0,10$, and $15 \%)$. A comparison between these concretes shows that the dime development of the compressive strengths of the concretes containing a larger quantity of SF is somewhat delayed over the first days of their ageing (Figure 1 and Table 4). The increased proportion of SF in the concrete has a favourable effect on the latter's compressive strength after the first days of ageing (Figure 2). 


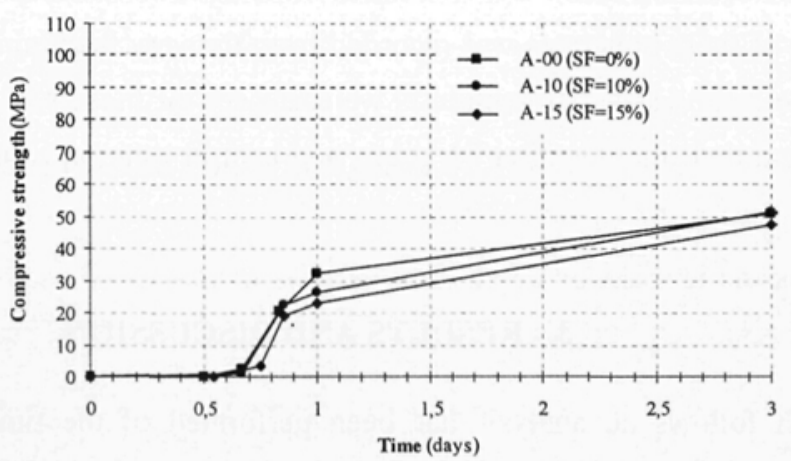

Fig. 1: Time development of the compressive strength of concretes A-00, A-10 and A-15 in the first three days.

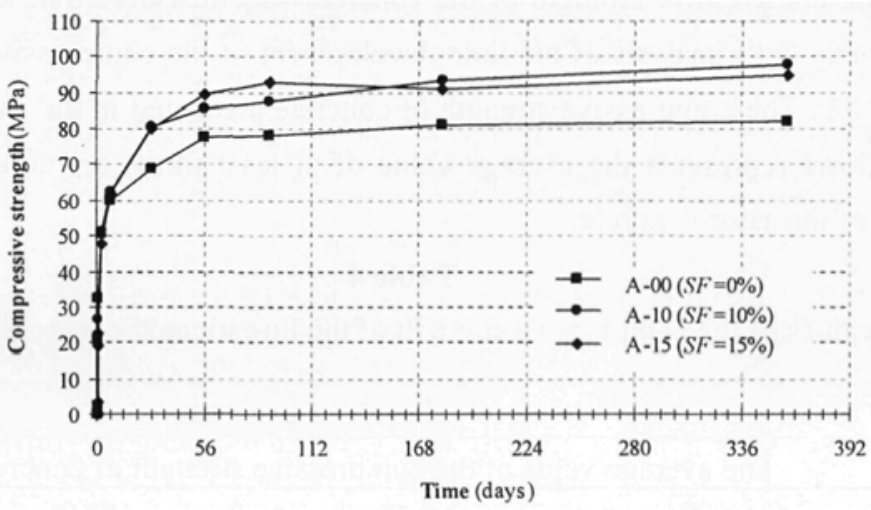

Fig. 2: Time development of the compressive strength of concretes A-00, A-10 and A-15.

For the initiation of the pozzolanic reaction between the SF and the calcium hydroxide it is necessary that the previous reaction between the cement and the water, one of whose products is calcium hydroxide, takes place. In these reactions the reason for the slower increase in the compressive strength of the concrete is apparent. Since the mixes dealt with here contained the same amount of binder (i.e. cement + SF), as the quantity of SF was increased the quantity of cement was decreased. Thus during the first hours of concrete hardening more cement hydration products occur, which means that the compressive strength of concrete without SF is greater than that of concrete with SF. At an age of 1 day the compressive strength of the concrete without SF, designated A-00, was 1.42 times greater than that of the concrete designated A-15, whose binder contained $15 \%$ of SF. In the case of later ages, i.e. after approximately 7 days, the considerable quantity of calcium hydroxide, which occurred as a consequence of the hydration of cement, has probably already reacted with the $\mathrm{SF}$ into calcium silicate hydrate, and so the hardened cement paste in the concrete with SF has improved quite a lot. Due to its high degree of fineness the SF densifies the structure of the hardened cement paste and improves the bond between the aggregate and the hardened cement paste, resulting in higher strength of the hardened concrete. At an age of both concretes of 56 days, the compressive 
strength of the concrete A-15, whose binder contained $15 \%$ of SF, was 1.15 times greater than the compressive strength of the concrete A-00, whose binder did not contain SF.

The time development of the compressive strength of concretes C-00 and C-10, which is shown in Figure 5 , confirms the previously mentioned hypothesis that the initial rate of increase of the compressive strength of concrete decreases as the amount of SF in the binder is increased. The two concretes C- 00 and C-10 are, according to their composition, the same as the concretes A-0 and A-10, except that they contain, instead of sedimentary aggregate, mainly metamorphic aggregate. The results shown in Figures 6 and 8 confirm the hypothesis that, in the case of concretes having an age greater than 7 days, the SF has a positive effect on the size of their compressive strengths.

Figure 3 shows the time development of the compressive strength of the investigated concretes B- 00 and B-10, which contained 0 and $10 \%$ SF. Both of these concretes contained $400 \mathrm{~kg}$ of binder, and had a W/B ratio of 0.4 . They contained the ordinary portland cement CEM I 52.5R, which had the maximum cement fineness $\left(440 \mathrm{~m}^{2} \mathrm{~kg}^{-1}\right)$ in comparison with the other investigated types of cement. During the first three days of their ageing, the time development of the compressive strength of both concretes was almost the same (Figure 3). The time development of the compressive strengths of these two concretes is also very similar after an age of 3 days (Figure 4). This is the consequence of the high specific surface area and large quantity of cement used.

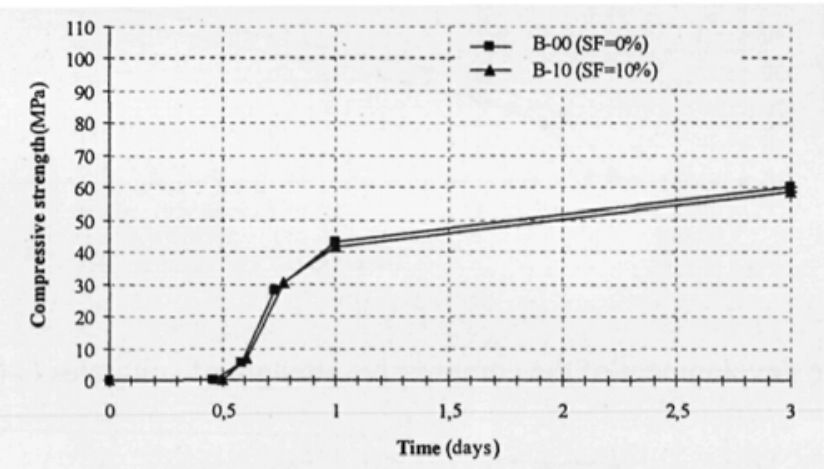

Fig. 3: Time development of the compressive strength of concretes B-00 and B-10 in the first three days

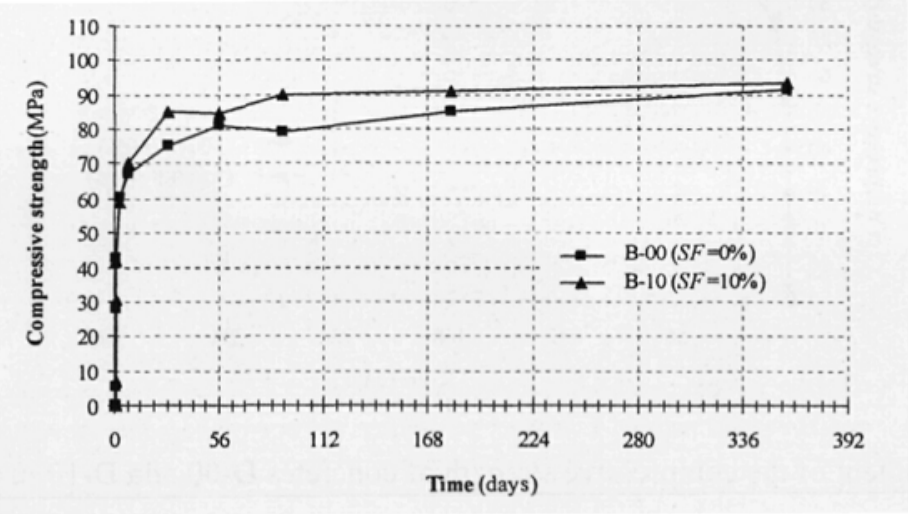

Fig. 4: Time development of the compressive strength of concretes B-00 and B-10 


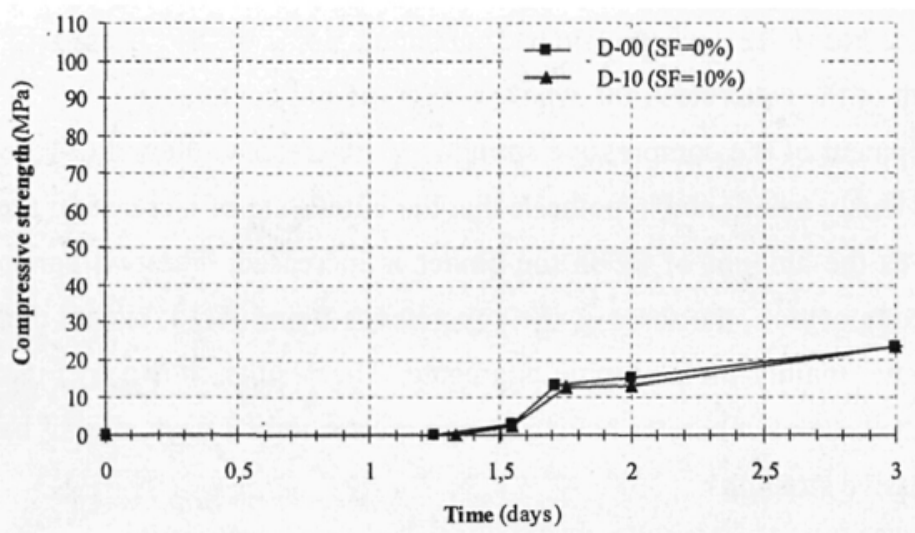

Fig. 5: Time development of the compressive strength of concretes $C-00$ and $C-10$ in the first three days.

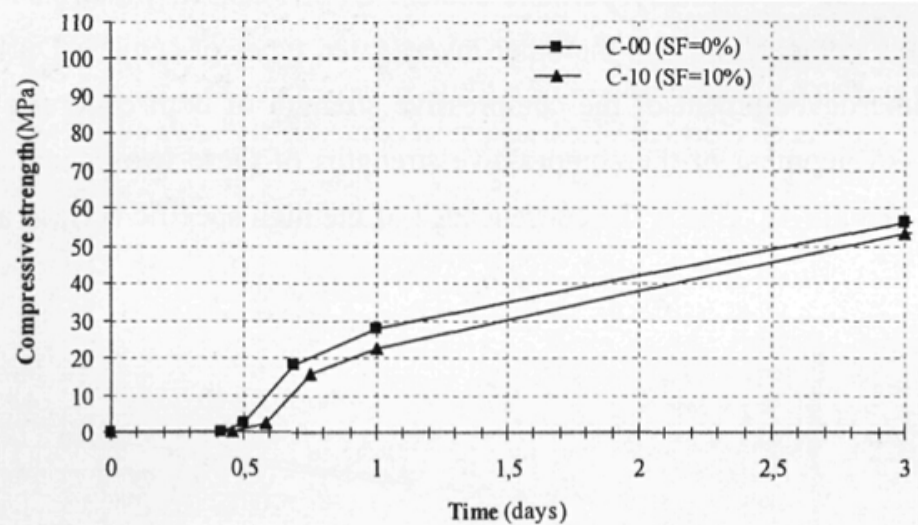

Fig. 6: Time development of the compressive strength of concretes $\mathrm{C}-00$ and $\mathrm{C}-10$.

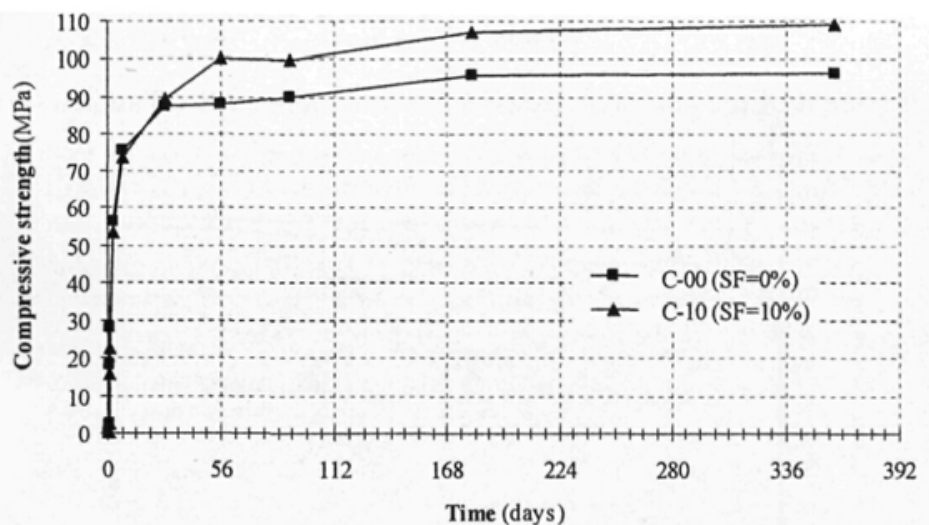

Fig. 7: Time development of the compressive strength of concretes D-00 and D-10 in the first three days. 


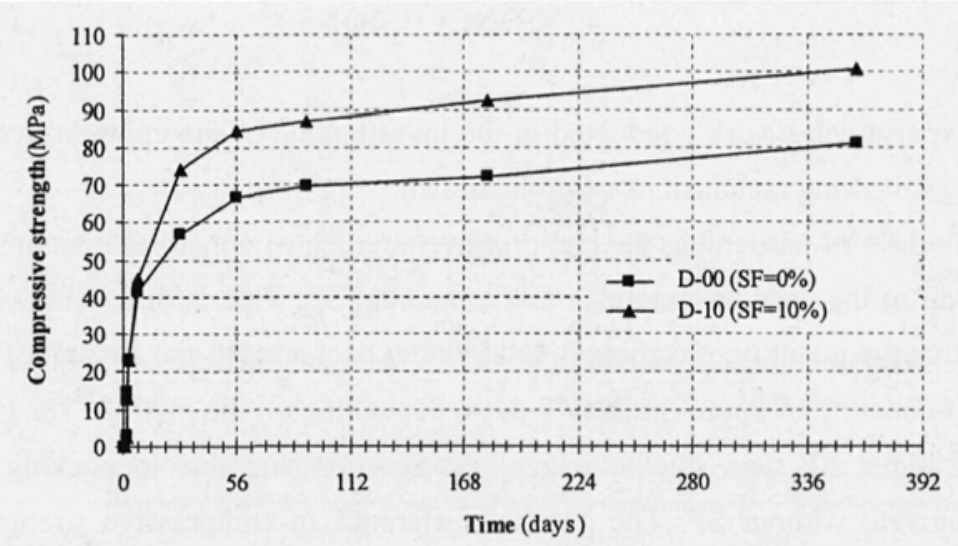

Fig. 8: Time development of the compressive strength of concretes D-00 and D-10.

Since, due to the large specific surface area of the cement, allowing for a sufficient quantity of water, there is more hydrated cement over a given period of time in comparison with cements having smaller specific surface areas, and the structure of the hardened cement paste is stronger, for this reason the SF has a smaller effect. It can thus be concluded that, with the gradual increasing of the specific surface area of the cement, the effect of the SF on the compressive strength of the concrete is reduced. In the case of concretes containing SF there is less cement than in the case of concretes not containing SF. Since, in the case of the used cement, the predominant mineral is alite, and it is well known that in the case of the hydration of alite about three times as much calcium hydroxide is produced as in the case of the hydration of belite, the effect of the pozzolanic reaction of the SF with the calcium hydroxide becomes noticeable very early on in the hardening process. In its further course the pozzolanic reaction can give the concrete a higher compressive strength.

The concretes D-00 and D-10 had the same composition as the concretes A-00 and A-10 (0 and $10 \%$ of $\mathrm{SF}, \mathrm{W} / \mathrm{B}=0.4,400 \mathrm{~kg}$ of binder per $\mathrm{m}^{3}$ of concrete), but contained cement with a low heat of hydration. This cement contained less alite and more belite than the other two used cements (see Table1). It is well-known /7/, that the hydration of alite contributes the most towards the initial strength of the hardened cement paste, whereas the hydration of belite contributes the most to the latter final strength. In the given case of cement with a small amount of alite, the initial strengths are low, and for this reason the effect of SF in the first three days was almost negligible. Apart from this, in the case of the hydration of belite less calcium hydroxide occurs than in the case of the hydration of alite, which means that in the case of cement consisting mainly of belite there is less calcium hydroxide available for the relatively rapid pozzolanic reaction with the SF. 


\section{CONCLUSIONS}

Based on the experimental work conducted in the investigation of the compressive strength development of SF concretes, the following conclusions could be drawn:

- In the first three days of hardening, the compressive strength of concretes containing added SF increases more slowly than in the case of concretes not containing SF. This is due to the pozzolanic reaction and due to the fact that the quantity of cement in total binder decreases as the amaunt of SF increases.

- After the age of concrete of approximately 7 days, depending on the mixture, the compressive strength of concretes with added SF was, due to pozzolanic reaction and due to packing effect, larger than of comparative concrete without SF. The greatest difference in compressive strength of SF concrete and comparative concrete without SF is observed at concretes containing predominantly belitic cement.

- By increasing the specific surface area of the cement, the effect of the SF on the increase of the compressive strength of the concrete is reduced.

\section{REFERENCES}

1. Goldman A., Bentur A., The influence of microfillers on enhancement of concrete strength, Cem. Concr. Res. 23 (4) (1993) 962-972.

2. Isaia G.C., Gastaldini A.L.G., Morases R., Physical and pozzolanic actions of mineral aditions on the mechanical strength of high performance concrete, Cem. Concr. Compos. 25 (1) (2003) 69-76.

3. Merrit F.S., Ricketts J.T., Building design and construction handbook, Mc Graw-Hill, 1994.

4. Goldman A., Bentur A., Bond effects in high-strength silica-fume concretes, ACI Mat. Jour. 86 (5) (1989) 440-447.

5. Saje D. Compressive strength and shrinkage of high strength concrete, $\mathrm{PhD}$. Thesis, Faculty of Civil and Geodetic Engineering, University of Ljubljana, 2001 (in Sloveniah).

6. European Committee for Standardization: CONCRETE - Specification, performance, production and conformity, European Standard, EN 206, 2000.

7. Neville A.M., Properties of concrete, Longman, UK, 1995. 